\title{
Survey of antimony workers: mortality 1961-1992
}

\author{
R D Jones
}

\begin{abstract}
The mortality of a census population and a prospective cohort of men employed on an antimony smelter in the north east of England was followed up from 1961-1992. The workers studied were exposed to a variety of agents including antimony and its oxides, arsenic and arsenic oxides, sulphur dioxide, and polycyclic aromatic hydrocarbons. The regional mortality rates were used to calculate expected deaths and a group of zircon sand workers employed on the site were used as a comparison group. For the census population of men working on the smelter before 1961 a significant increase in deaths from lung cancer was found (32 observed $v 14.7$ expected, $P<0.001)$. A similar excess was seen among maintenance men (12 observed $v 5.3$ expected $P=0 \cdot 016)$. No such excess was found in the cohort recruited after 1960 (5 observed $v \quad 9.2$ expected, maintenance workers 3 observed $v \quad 2.8$ expected). There was evidence of a minimum latency period of around 20 years between first exposure and death from lung cancer. No evidence was found for a correlation between length of time worked and mortality from lung cancer. The results show that an increased risk of lung cancer existed in the workers employed before 1961, but it was not possible to attribute this excess to any particular agent. Mortality analysed by five year calendar periods of first exposure show a lessening of effect after 1955. Although the power of the study is clearly less for more recent periods of exposure the absence of any excess in the population after 1960 is encouraging.
\end{abstract}

(Occup Environ Med 1994;51:772-776)

Keywords: antimony, lung cancer, smelter

There has been considerable debate about the possible carcinogenicity of antimony compounds. The data available are not plentiful and the few laboratory studies have shown conflicting results.

In the first of these, an inhalation study conducted by Watt, lung tumours were reported in female rats exposed to antimony trioxide. ${ }^{1}$ Female miniature pigs similarly exposed did not develop tumours. The scientific design of the study has been criticised and the accuracy of exposure measurement questioned. ${ }^{2}$

A rat study by Groth et al reported lung tumours in $27 \%$ of the exposed females but no evidence of carcinogenicity was found in exposed male rats. ${ }^{3}$ Once again the control of exposure levels in this study has been questioned, but there also seems to have been a confounding exposure to arsenic.

Newton and Daly later reported a one year inhalation study in Fischer 344 rats examining the results of exposure to $0,0.05,0.5$, and $5 \mathrm{mg}$ of particulate antimony trioxide per $\mathrm{m}^{3}$ of air with 65 male and 65 female animals in each exposure group. ${ }^{4}$ Neoplasms occurred sporadically in both treated and control animals.

From these data it can be concluded that the carcinogenic effect of antimony trioxide in animals is to say the least inconclusive.

This paper describes the only substantial human study to date. It was originally set up by the local Medical Inspector of Factories in 1961, after anecdotal suggestions of a link between exposure to antimony and death from lung cancer in men employed at another factory in the north west of England.

\section{Subjects and methods \\ BACKGROUND}

The population studied was recruited from an antimony works in the north east of England where roasting of antimony ore goes back some 60-70 years. Work practices and raw materials have altered over the years with fluctuations in the availability of particular ores and world demand for antimony compounds. Antimony ore brought into the site has been used to produce antimony metal, antimony alloys, and antimony trioxide.

Until the early 1970s there had been a considerable demand for antimony as a constituent of lead alloys in the manufacture of lead acid batteries. Such alloys were made in considerable quantities containing as much as $80 \%$ lead and $10 \%$ arsenic. With the rapid decline in manufacture of this type of accumulator the market for antimony metal all but disappeared so that antimony metal and its alloys were not made on this site after 1973 .

Although antimony oxide was used in paints and alloys before the war, it was in the early 1950s that its use as a flame retardant began, thereby considerably increasing demand for the compound. The antimony plant is currently dedicated to manufacture of the trioxide. 
At different times various ores have been used but over the past 30 years or so the bulk of the ore imported has been a South African sulphide ore containing about $60 \%$ of antimony and up to $0.5 \%$ of arsenic. Ores were usually roasted in open hearth, rotary, or blast furnaces before the revolatilisation of the roasted product to produce good quality trioxide of antimony: but different techniques were used at various times.

During the years when arsenical antimony was being manufactured the arsenic content of the ore was not sufficient to make the richer arsenic alloys, so that arsenic metal and its trioxide were brought in to do this. Thus men working in the antimony plant would have experienced variable occupational exposure to lead, metallic antimony, metallic arsenic, antimony trioxide, and arsenic trioxide. There would also have been exposure to the many products of combustion in the various furnaces used, including emissions of polycyclic aromatic hydrocarbons. Also, the sulphide content of the ore would have given rise to exposure to sulphur dioxide.

The actual size of the workforce has varied over the years. In the past it would have comprised some 200 men working a four-shift system, and an additional 40 day workers. Now the company operates a three-shift system, employing only 21 shift workers and an additional 10 day workers. Thus the actual workforce employed on antimony has decreased from around 240 in the 1950 s to some 30 or so now.

The other main activity carried out on site, and the only substantial non-antimony process, is the milling of zircon sand. The sand is imported from Australia and is either dry or wet milled. The process is purely physical, there being no chemical change, and once the sand has been rendered to the required particular size it is despatched either to the foundry or ceramic industry. Until recently the zircon and antimony workers have worked separately, although very occasionally it may have been necessary to move a man temporarily from one process to the other. The wages for both types of work have always been similar and both plants largely use non-skilled manual labour. The zircon plant was commissioned in 1950 .

\section{POPULATIONS}

At the start of the study all people in the company's employ on 1 January 1961 were recruited into the survey, and all workers joining after that date have been similarly included. For the purpose of this analysis we have only considered men with at least three months employment and subdivided the population into four occupational groups:

(a) antimony workers;

(b) maintenance workers;

(c) zircon workers;

(d) others (this category includes office workers and management staff).

Because permanent job transfer did take place, an antimony worker is defined here as any person who worked in the antimony plant for at least three months regardless of his present or last occupation. Transfer from another department into the antimony smelter would have been highly unusual, so that antimony workers would mostly have started as such. Other survey subjects have been assigned to maintenance, zircon, or other groups, depending on their last occupation. Women have been excluded from this analysis as very few women $(<10)$ were ever employed on the antimony plant. The results for the census population that comprised all the men who worked at the company on 1 January 1961 and the cohort of men recruited prospectively after that date, have been calculated separately as the before 1961 and after 1960 exposed groups.

\section{TRACING OF POPULATION}

Identification details including full name, address, and date of birth, were noted and sent to the Office of Population, Censuses and Surveys (OPCS) for tracing and flagging on the National Health Service Central Register (NHSCR). Whenever OPCS received a death notification for any survey subject, a copy of the death certificate with the underlying cause of death coded according to the International Classification of Diseases (ICD) was sent to the investigators. Deaths that occurred before 1968 as well as those occurring in 1968 to 1978 were coded to the eighth revision of the ICD (ICD-8) and certificates relating to deaths in 1979 to 1987 were coded to the ninth revision (ICD-9).

\section{CALCULATION OF EXPECTED DEATH RATES}

Two sets of expected figures were worked out: the first based on national rates for England and Wales and the second based on local rates (Tyneside conurbation 1961-73, Tyne and Wear 1974-83). Man-years at risk were calculated for the population in separate decennial age periods for each year from 1 January 1961 to 31 December 1983. Appropriate age specific death rates were then applied to calculate the number of deaths expected for each cause of death considered.

The period of study spans three revisions of the ICD code-that is, the seventh revision (ICD-7) up to the end of 1967, ICD-8 from 1968 to 1978 , and ICD-9 from 1979 onwards. For the causes of death considered there is no practical difference between ICD-8 and 9. There are, however, some differences between ICD-7 and 8 for heart disease, respiratory disease, and diseases of the urinogenital system. Expected rates for the periods from 1961-67 were therefore calculated in terms of ICD-8. The methods (based on advice from OPCS) by which this was done are detailed in the next section.

Conurbation rates from OPCS for 1961 and 1962 were not divided separately into the 25-35, and 35-44 years age groups. Estimates of rates in the two separate age groups were calculated by splitting the deaths in the overall 25-44 year age group in the same proportions for 25-35, and 35-44 as were seen in 1965 . Figures for 1963 were not used because of the 
Table 1 Observed and expected deaths from the main causes of death

\begin{tabular}{|c|c|c|c|c|c|c|c|c|c|c|}
\hline & \multicolumn{2}{|c|}{ Antimony } & \multicolumn{2}{|c|}{ Maintenance } & \multicolumn{2}{|c|}{ Zircon } & \multicolumn{2}{|c|}{ Others } & \multicolumn{2}{|l|}{ Total } \\
\hline & Obs & $\operatorname{Exp}$ & Obs & $\operatorname{Exp}$ & Obs & $\operatorname{Exp}$ & Obs & $\operatorname{Exp}$ & Obs & $\operatorname{Exp}$ \\
\hline All deaths & 192 & 183.3 & 75 & 61.9 & 56 & $68 \cdot 6$ & 34 & $47 \cdot 4$ & 357 & $361 \cdot 2$ \\
\hline All neoplasm: & 69 & $\mathbf{5 4 \cdot 7}$ & 34 & $18 \cdot 2^{\star \star}$ & 14 & $20 \cdot 1$ & 7 & $14 \cdot 3$ & 124 & $107 \cdot 3$ \\
\hline Lung cancer & 37 & $23 \cdot 9^{\star}$ & 15 & $8 \cdot 1^{\star}$ & 5 & $8 \cdot 8$ & 6 & 6.1 & 63 & $46 \cdot 9^{\star}$ \\
\hline Stomach cancer & 2 & $4 \cdot 8$ & 1 & $1 \cdot 7$ & 2 & $1 \cdot 8$ & 0 & $1 \cdot 2$ & 5 & 9.4 \\
\hline Other neoplasms & 30 & $26 \cdot 0$ & 18 & $8 \cdot 4^{\star}$ & 7 & $9 \cdot 5$ & 1 & $7 \cdot 0^{\star}$ & 56 & $51 \cdot 0$ \\
\hline Circulatory disease & 72 & $84 \cdot 3$ & 20 & $28 \cdot 4$ & 33 & $31 \cdot 8$ & 20 & $21 \cdot 5$ & 145 & $166 \cdot 0$ \\
\hline Ischaemic heart disease & 49 & $60 \cdot 5$ & 12 & $19 \cdot 9$ & 23 & $22 \cdot 3$ & 16 & $15 \cdot 4$ & 100 & $118 \cdot 1$ \\
\hline Other circulatory disease $†$ & 23 & $23 \cdot 8$ & 8 & $8 \cdot 5$ & 10 & $9 \cdot 5$ & 4 & $6 \cdot 1$ & 45 & $47 \cdot 9$ \\
\hline Respiratary disease & 20 & $19 \cdot 8$ & 13 & $7 \cdot 5$ & 6 & $8 \cdot 2$ & 1 & $4 \cdot 8$ & 40 & $40 \cdot 2$ \\
\hline Genitourinary disease & 1 & $1 \cdot 4$ & 1 & 0.6 & 0 & $0 \cdot 7$ & 1 & 0.4 & 3 & $3 \cdot 3$ \\
\hline Accident and suicides & 9 & $7 \cdot 7$ & 4 & $2 \cdot 2$ & 3 & $2 \cdot 4$ & 2 & $2 \cdot 4$ & 18 & $14 \cdot 6$ \\
\hline Other causes $†$ & 21 & $15 \cdot 2$ & 3 & $5 \cdot 0$ & 0 & $5 \cdot 4$ & 3 & $4 \cdot 0$ & 27 & $29 \cdot 8$ \\
\hline
\end{tabular}

${ }^{\star} \mathrm{P}<0.05 ;{ }^{\star \star} \mathrm{P}<0.01$. Expected deaths were calculated from the Tyne and Wear rates. + Calculated by difference.

abnormal pattern of deaths in the early part of that year due to climatic conditions.

CALCULATION OF REFERENCE RATES FROM

THE ICD-8 FOR 1961-67

(1) Ischaemic heart disease (ICD-8 410-414) rates for 1961-7 have been calculated by combining figures for arteriosclerotic heart disease (ICD-7 420) and degenerative heart disease (ICD-7 421, 422).

(2) Respiratory disease (ICD-8 460-519) rates for 1961-7 have been calculated by combining figures for ICD-7 240, 241, and 470-527.

(3) Figures for diseases of the urinogenital system (ICD-8 580 to 629 ) are not available for 1961-7 but rates for nephritis, nephrosis, and hyperplasia of the prostate (ICD-8 580-584 and 600) are available. Estimates of death rates for urinogenital disease as defined by the ICD-8 in 1961-7 have been calculated by applying age and sex specific ratios between deaths in ICD-8 580-584 and 600, and the remainder of 580 to 629 in 1968 (the earliest year for which full information was available) to the death rates for nephritis, nephrosis, and hyperplasia of the prostate in the earlier years.

COMPARISON OF DEATHS

The observed numbers of deaths were then compared with the expected figures calculated as above. Differences between observed and expected deaths for all causes and selected diseases were tested for significance assuming a Poisson distribution.

\section{Results}

By 31 December 1992, 2508 people had been recruited into the survey of whom 356 were

Table 2 Observed and expected deaths from lung cancer, split between employees joining before and after 1 fanuary 1961

\begin{tabular}{|c|c|c|c|c|c|c|}
\hline & \multicolumn{2}{|c|}{ Before 1 fanuary 1961} & \multicolumn{2}{|c|}{ After 31 December 1960} & \multicolumn{2}{|c|}{ Total } \\
\hline & Obs & $\operatorname{Exp}$ & Obs & $\operatorname{Exp}$ & Obs & $\operatorname{Exp}$ \\
\hline $\begin{array}{l}\text { Antimony } \\
\text { Maintenance } \\
\text { Zircon } \\
\text { Others }\end{array}$ & $\begin{array}{r}32 \\
12 \\
2 \\
3\end{array}$ & $\begin{array}{c}14 \cdot 7^{\star \star} \\
5 \cdot 3^{\star} \\
5 \cdot 8 \\
2 \cdot 7\end{array}$ & $\begin{array}{l}5 \\
3 \\
3 \\
3\end{array}$ & $\begin{array}{l}9 \cdot 2 \\
2 \cdot 8 \\
2 \cdot 9 \\
3 \cdot 4\end{array}$ & $\begin{array}{r}37 \\
15 \\
5 \\
6\end{array}$ & $\begin{array}{c}23 \cdot 9^{\star} \\
8 \cdot 1^{\star} \\
8 \cdot 8 \\
6 \cdot 1\end{array}$ \\
\hline Total & 49 & $28 \cdot 5$ & 14 & $18 \cdot 4$ & 63 & $46 \cdot 9$ \\
\hline
\end{tabular}

Footnotes as for table 1 . women and 700 men with $<3$ months service. Thirty two $(3 \%)$ of the 1452 remaining men were not traced by OPCS. Of the 1420 traced men who form the basis of the analysis, 357 had died and 29 emigrated by the end of 31 December 1992. Thus the trace rate for the population overall was $97 \%$ and was not less than $96 \%$ for any of the occupational categories studied.

Table 1 shows the overall mortality, and mortality from selected causes for the four occupational groups. There is an excess of all neoplasms in the antimony workers (69v $54 \cdot 7, P=0.07$ ), due to a significant excess of lung cancer ( $37 v 23.9, \mathrm{P}=0.016)$. There is an excess of all neoplasms for maintenance men (34 v 18.2, $\mathrm{P}=0.002)$ due to an increase in mortality from lung cancer (15 $v 8 \cdot 1$, $\mathrm{P}=0.038$ ), and other neoplasms (18 $v 8.4$, $\mathrm{P}=0.006)$, but not for stomach cancer ( $1 v$ 1.7).

There is a deficit of mortality from all causes in the zircon workers that does not seem to be due to a favourable outcome from any particular disease group. The antimony and maintenance workers show evidence of a healthy worker effect for ischaemic heart disease. There is no evidence of any such beneficial effect for respiratory disease, indeed the maintenance workers have a non-significant excess of mortality in this category. (13 observed $v 7.5$ expected, $\mathrm{P}=0.086$ ).

Table 2 shows observed and expected deaths from lung cancer separating employees who joined before 1 January 1961 and those who joined after 31 December 1960. For the antimony workers before 1961 there is a significant excess of lung cancer $(32 \mathrm{v} 14 \cdot 7, \mathrm{P}<$ $0.001)$. A significant excess is also seen in the maintenance workers before 1961 (12 v 5.3, P $=0.016$ ). Evidence of an excess of lung cancer is not found in the zircon and miscellaneous groups, nor in any of the groups recruited after 31 December 1960.

Table 2 shows that over $60 \%$ of the expected mortality from lung cancer for the whole survey population is in the antimony and maintenance workers before 1961. This reflects the relatively large proportion of manyears at risk contributed to the study by these groups.

Table 3 shows deaths from lung cancer in antimony workers by calendar year of first exposure to antimony. It shows an excess in 
Table 3 Analysis of deaths from lung cancer in antimony workers by calendar period of first employment

\begin{tabular}{lcc}
\hline First date of exposure & Obs & Exp \\
\hline Before 31 December 1940 & 6 & $1 \cdot 7^{\star}$ \\
1 January 1941-31 December 1945 & 3 & $1 \cdot 6$ \\
1 January 1946-31 December 1950 & 4 & $0 \cdot 9^{\star}$ \\
1 January 1951-31 December 1955 & 4 & $1 \cdot 3$ \\
1 January 1956-31 December 1960 & 15 & $9 \cdot 2$ \\
1 January 1961-31 December 1965 & 1 & $2 \cdot 3$ \\
1 January 1966-31 December 1970 & 4 & $5 \cdot 7$ \\
1 January 1971-31 December 1975 & 0 & $1 \cdot 1$ \\
1 January 1976-31 December 1980 & 0 & $0 \cdot 1$ \\
1 January 1981-31 December 1985 & 0 & $0 \cdot 0$ \\
1 January 1986-30 December 1990 & 0 & $0 \cdot 0$ \\
Total & 37 & $23 \cdot 9$ \\
\hline
\end{tabular}

Footnotes as for table 1 .

Table 4 Analysis of deaths from lung cancer in antimony workers by years since first exposure to antimony

\begin{tabular}{lcc}
\hline Follow up $(y)$ & Obs & Exp \\
\hline$>1$ & 0 & $0 \cdot 2$ \\
$1-5$ & 0 & $1 \cdot 0$ \\
$6-10$ & 3 & $2 \cdot 1$ \\
$10-20$ & 7 & $7 \cdot 9$ \\
$21-30$ & 20 & $8 \cdot 4^{\star \star}$ \\
$31-40$ & 6 & $3 \cdot 1$ \\
$41-50$ & 1 & $0 \cdot 9$ \\
$>50$ & 0 & $0 \cdot 2$ \\
Total & 37 & $23 \cdot 9 \star$ \\
\hline
\end{tabular}

Footnotes as for table 1 .

lung cancer for all five-year periods of first exposure up to 31 December 1960. People who started work before 1955 show an excess of three to four times the lung cancer expected, but the group who started work from 1955 to 1960 show less than a doubling of lung cancer, whereas people who started work after 1960 show no such excess.

Table 4 shows the analysis of deaths from lung cancer in antimony workers by years since their first exposure to antimony. It can be seen that $<20$ years after first exposure there is no excess of lung cancer but that after this a significant twofold excess emerges.

Table 5 presents the mortality of antimony workers from lung cancer by years of exposure. It shows no trend of greater risk with increased years of exposure.

\section{Discussion}

The survey was set up to test the original hypothesis that an excess of lung cancer was being experienced by the antimony workers at this plant. The results of this mortality analysis

Table 5 Analysis of deaths from lung cancer in antimony workers by years of exposure to antimony

\begin{tabular}{|c|c|c|c|c|}
\hline \multirow[b]{2}{*}{ Exposure $(y)$} & \multicolumn{2}{|c|}{ Before 1 fanuary 1961} & \multicolumn{2}{|c|}{ After 31 December 1960} \\
\hline & Obs & $\operatorname{Exp}$ & Obs & $\operatorname{Exp}$ \\
\hline $\begin{array}{l}<1 \\
1-5 \\
5-10 \\
10-15 \\
15-20 \\
20-25 \\
25-30 \\
30-35 \\
>35\end{array}$ & $\begin{array}{l}2 \\
5 \\
4 \\
5 \\
4 \\
3 \\
5 \\
3 \\
1\end{array}$ & $\begin{array}{l}0.7 \\
2.9 \\
2.0 \\
1.7 \\
1.9 \\
1.3 \\
1.4^{\star} \\
1.1 \\
1.6\end{array}$ & $\begin{array}{l}1 \\
3 \\
0 \\
0 \\
0 \\
1 \\
0 \\
0\end{array}$ & $\begin{array}{l}4 \cdot 5 \\
2 \cdot 6 \\
0 \cdot 6 \\
0 \cdot 5 \\
0 \cdot 5 \\
0 \cdot 5 \\
0 \cdot 1 \\
0\end{array}$ \\
\hline Total & 32 & $14 \cdot 7^{\star \star}$ & 5 & \\
\hline
\end{tabular}

Footnotes as for table 1 . show a significant excess of lung cancer among antimony smelter workers, and maintenance workers. The excess in smelter workers is confined to those joining before 1961 and the excess in lung cancer does not appear until 20 years after first exposure to the antimony process. There is an excess of lung cancer for workers first exposed in all the five-year calendar periods before 1960 .

These results suggest that before 1960 antimony workers were exposed to some carcinogen in the workplace. Because at this stage of follow up very few of the employees after 1960 were first exposed to the antimony process $>20$ years previously, and because the lung cancer excess does not show until 20 years after first exposure, it is not possible to be certain whether this carcinogenic effect persisted after 1960 . The analysis of mortality by time since first exposure to the process (table 4) does not suggest an increasing effect after a 20 year latency, so that the relatively smaller excess seen for people first exposed in the late 1950 s may indicate a lessening of carcinogenic exposure. When considering the results from the population before 1961 shown here, it must be remembered that this particular group is a census population and will be subject to survivor bias - that is, this group will selectively include several men who have worked at the plant for a substantial time, and individuals who for various reasons (including ill health) have left the job after shorter spells of employment will be underrepresented. Thus people surviving any rigours or hazards of such employment will be over-represented in the population before 1961.

It is generally accepted by occupational physicians that because of the need for maintenance personnel to work in many different areas and attend to plant at times of malfunction and breakdown, their exposure to hazardous agents in the workplace may be at least as great and sometimes greater than that of the operators. The finding of an excess incidence of cancer among maintenance workers is therefore consistent with the original hypothesis of an excess of lung cancer in smelter workers.

The true relevance of the excess of all neoplasms among maintenance staff is less clear. Firstly, any excess in these cancers was not an original hypothesis and secondly, other neoplasms is not a specific disease group. My view is that it would not have been correct to present expected rates for disease groups other than those determined before analysis. Subsequent to the results of the analysis being seen, however, inspection of the coded underlying causes of death for the 18 other neoplasms in maintenance men showed that six of these were due to cancers of the large bowel. This is most likely to be a spurious finding but it might stimulate examination of other relevant studies and data sets.

The lack of any healthy worker effect for respiratory disease in antimony, maintenance, or zircon workers is interesting and contrasts with the favourable mortality experienced by 
the antimony and maintenance workers for ischaemic heart disease. This may be indicative of a non-specific occupational effect on mortality from respiratory disease, but the small numbers involved do not allow any further inference.

From the data here it is not possible to implicate any particular substance evolved during the smelting process but the evidence for excess lung cancer in workers smelting copper ore containing arsenical impurities is well documented.$^{67}$ Exposure to arsenic fume and arsenic trioxide have probably been responsible for some, and possibly all, of the excess of lung cancer found in this population. There are also other possible confounding factors. Blast furnace emissions would have included polycyclic aromatic hydrocarbons some of which are known carcinogens. Some of the men would have spent some time working in the local ship building industry and thereby received occupational exposure to asbestos. This cannot be a pure confounder in itself because the same holds good for the zircon workers. This asbestos exposure, however, could well have acted synergistically with whatever carcinogenic agent was associated with smelter work and thereby increased the potency of that exposure.

Smoking data on this group of men show that as yet all lung cancer decedents whose smoking habit was known were smokers, but given the prevalence of that habit during the time of recruitment of this population, this is not especially surprising, particularly if the carcinogenic agent operated synergistically with smoking. (The prevalence of smoking among workers in 1961 was $72 \%$.) To explain the excess mortality from lung cancer found here by an increase in smoking habit, one would have to postulate a $100 \%$ smoking habit in these men at an above average tobacco consumption. This would be extremely unlikely and the absence of any excess of lung cancer among the zircon workers who were drawn from the same population would suggest that the excess of lung cancer in the antimony workers must be explained by some occupational factor. Over the study period there have been improvements in plant and greater attention paid to the problem of fume exposure which have considerably reduced the exposure to various substances emitted during the roasting and smelting of ores. Hopefully this, with the end of the manufacture of arsenic alloy, will have greatly reduced, if not eradicated, any carcinogenic hazard in the antimony plant. Because of the latent period between exposure and death from lung cancer, however, it is not possible to draw valid conclusions about the current existence of any carcinogenic risk.
Weaknesses of the study include the absence of good data on levels and type of exposure or smoking habit. The manner in which the population is structured means that for the population before 1961 there is inevitably some confounding between years of exposure, time since exposure, and calendar period of first exposure. The inadequacy of even a 20 year follow up when assessing a carcinogenic effect with considerable latency, has already been discussed. The study would have profited from a larger non-antimony exposed group than the zircon population can provide. Maintenance staff would have worked on the antimony plant at times of breakdown of equipment and in situations particularly likely to allow exposure to raw materials and byproducts, as well as end products themselves. Given the excess of lung cancer in the antimony workers a similar finding in the maintenance men is not, therefore, surprising.

In conclusion, the study shows an excess of lung cancer among production and maintenance workers at an antimony smelter where exposure to arsenic compounds would also have occurred. This excess of lung cancer is significant in people who have worked in the smelting process and approaches a threefold increase in the population before 1961. The results are consistent with a carcinogenic agent having a latency of 20 years. It is not yet possible to be certain whether the excess of lung cancer that existed before 1961 has persisted in the population after 1960 .

This paper has been made possible by the work of many. It is not possible to mention all those who have contributed to the project over the years but without their substantial contribution this paper could not have been written. I would like to thank OPCS for their invaluable help without which efficient follow up of the population could not have been achieved. I also acknowledge the cooperation of the company management and trade unions. Dr M Greenberg has provided valuable information on the history of the study, and I am grateful to Professor R I McCallum CBE for his advice and comments.

1 Watt WD. Chronic inhalation toxicity of antimony trioxide: validation of the threshold limit value: Detroit, MI Wayne State University, 1983. (Doctoral dissertation.)

2 United States Environmental Protection Agency. Antimony metal, antimony trioxide and antimony sulphide. Response to the interagency testing committee. phide. Response to the inte
Federal Register 1983;48:717.

3 Groth DA, Stettler LE, Burg JR, Busey WM, Grant GC, Wong $\mathrm{L}$. Carcinogenic effects of antimony trioxide and antimony ore concentrate in rats. $\mathcal{F}$ Toxicol Environ Health 1986;18:607-26.

4 Newton PE, Daly IW. A one year inhalation toxicity study of antimony trioxide in the rat (with a one year recovery period). US: Bio/dynamics, 1990; (Report No 83-7647.)

5 Newton PE, Bolte HF, Daly IW, Pillsbury BD, Terrill JB Drew RT, et al. Sub chronic and chronic inhalation studies of antimony trioxide in the rat. Fund Appl Toxicol 1994;22:561-76.

6 Pinto SS, Henderson V, Enterline PE. Mortality experience of arsenic exposed workers. Arch Environ Health 1978;33:325-31.

7 Wall S. Survival and mortality patterns among swedish smelter workers. Int $\mathcal{f}$ Epidemiol 1980:9:78-87. 